\title{
Movimentos emaranhados: travestis, movimentos sociais e práticas acadêmicas
}

\author{
Gilson Goulart Carrijo' (iD 0000-0001-5209-3884 \\ Keila Simpson ${ }^{2}$ (i) 0000-0002-8916-5500 \\ Emerson Fernando Rasera' ${ }^{1}$ (D) 0000-0001-6289-2313 \\ Marco Aurelio Máximo Prado ${ }^{3}$ (iD) 0000-0002-3207-7542 \\ Flavia Bonsucesso Teixeira' ${ }^{1}$ (D) 0000-0001-5605-636X \\ 'Universidade Federal de Uberlândia, Uberlândia, MG, Brasil. 38408-100 \\ ${ }^{2}$ Associação Nacional de Travestis e Transexuais, Salvador, BA, Brasil. 40040-330 - \\ presidencia.antra@gmail.com \\ 3Universidade Federal de Minas Gerais, Belo Horizonte, MG, Brasil. 31270-901
}

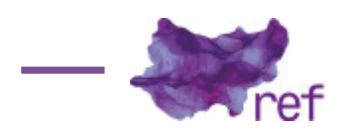

Resumo: As narrativas sobre as travestis e transexuais integram um conjunto significativo de trabalhos acadêmicos no Brasil, revelando diferentes formas de (re)contar a sociabilidade delas. Esse artigo é uma proposta coletiva de (re)pensar o lugar da academia na (re)produção das vidas travestis, a partir da construção de uma estratégia narrativa que inclua a perspectiva de uma epistemologia situada na experiência. Nosso argumento é que diferentes estratégias de pesquisas podem reconstruir e ressignificar a discussão sobre o "lugar de fala" que tem marcado uma tensa relação entre academia e movimento social.

Palavras-chave: travestis; movimento social; produção acadêmica; documentário

Tangled Movements: Travestites, Social Movements, and Academic Practices

Abstract: The narratives about transvestite and transgender have integrated a significant set of academic works in Brazil, revealing different ways of (re)telling their sociability. This article is, of the construction of a narratives strategy that includes the perspective of an epistemology situated in the experience, a collective proposal tore think the place of the academy in there production of transvestite and transgender lives. Our argument is that different research strategies can reconstruct and resignify the discussion about the "place of speech" that has marked a tense relationship between academia and social movement.

Keywords: Transvestite; Social Movement; Academic Works; Documentary

\section{Introdução}

Este artigo se inspira na pesquisa etnográfica sobre a trajetória de vida de Keila Simpson e seu registro documentário' que articulou a narrativa pessoal e seus entrelaçamentos com o movimento de travestis e transexuais no Brasil. Produzida em perspectiva situada, esta proposta enfrentou desafios técnicos e teóricos ao repensarmos a relação entre cinema, experiências e conhecimento científico desde um lugar deslocado para a periferia, ainda que utilizando chaves conceituais que foram forjadas no centro.

'Mais informações sobre o documentário, ver filmografia - nas referências ao final. 
José Jorge de CARVALHO (2001), ao revisitar as ideias de Edward Said, ${ }^{2}$ Gayatri Spivak ${ }^{3}$ e Homi Bhabha, ${ }^{4}$ nos enreda no compromisso de pensar sobre qual antropologia fazemos nos países periféricos, que etnografia construímos na relação com "nossos (nós os) nativos". Produzir um filme documentário com uma travesti permitiu questionar o descentramento/deslocamento que estamos produzindo na academia ao transitar por entre as vidas travestis.

O filme etnográfico não se configura como novidade no cenário da antropologia. Está presente desde as grandes expansões colonialistas, realizadas no final do século XIX e início do século XX, resultado do domínio tecnológico europeu que possibilitava os registros e as várias expedições etnográficas. Embora Franz Boas não tivesse a intenção de realizar um filme etnográfico, tornou-se um dos primeiros pesquisadores a utilizar fotografias e filmes no trabalho de campo por acreditar que a descrição e análise de certas práticas culturais exigiriam o registro de imagens (Clarice EHLERS PEIXOTO, 1999).

O trabalho de Margaret Mead, ${ }^{5}$ nos anos de 1940, inaugurou o debate sobre verdade/objetividade das imagens problematizando as informações audiovisuais como resultados de uma seleção operada pelo antropólogo/cineasta sendo, por esse motivo, impregnadas de subjetividade e escolhas como qualquer outra informação coletada pelas técnicas tradicionais de pesquisa. Ou seja, a imagem passa a ser entendida e utilizada como uma representação do antropólogo ligada diretamente às suas maneiras de ver e se relacionar como o mundo (João RAPAZOTE, 2007).

Jean ROUCH (1971), posicionado como cineasta e antropólogo, apresentou no filme Petit à Petit (1971) o uso das imagens e sons para compor uma etnoficção a partir da antropologia compartilhada. O filme conta a história de supostos empresários africanos que viajam até Paris para encomendar um projeto arquitetônico (uma nova sede para a empresa deles) e são aconselhados a estudar a vida e os costumes dos habitantes daquela cidade para então compreender a proposta de construir um edifício. Com esse enredo o filme permite ao autor aparentemente inverter a relação pesquisador/pesquisado, ou melhor, entre os colonizadores e os colonizados.

Possibilitar que os atores de nacionalidade africana se apresentassem representando empresários africanos em Paris e (re)apresentassem sua versão sobre os europeus (pesquisadores do europeu) afirmava a potência criativa da ficção que eles inventaram nas construções do outro. Os absurdos de algumas cenas parecem funcionar como lembrete para o espectador de que se trata de uma ficção como, por exemplo, o diálogo estabelecido no encontro no escritório do arquiteto, ao mesmo tempo em que a aproximação com questões teóricas (a menção ao padrão nutricional dos franceses em contraposição às pesquisas realizadas por europeus no continente africano) demonstra a crítica do pesquisador Jean Rouch e seus colaboradores ao etnocentrismo (Sandra Straccialano COELHO, 2016).

A proposta de descentramento produzida por Jean Rouch estaria para além da superação da separação dos olhares dos dois sujeitos construídos pela disciplina: o do etnógrafo (o civilizado) e o do nativo por ele olhado (o primitivo) (José Jorge de CARVALHO, 2001). Ele possibilitou que o olhar do outro, nativo, realizasse efeitos na produção do filme e redefinisse os caminhos do etnógrafo, embora a origem do olhar tenha se mantido presa à posição de um pesquisador europeu.

Foto 1: Frames do documentário "Um atentado violento ao pudor", dirigido por Gilson Goulart e Keila Simpson, Brasil - 2017.

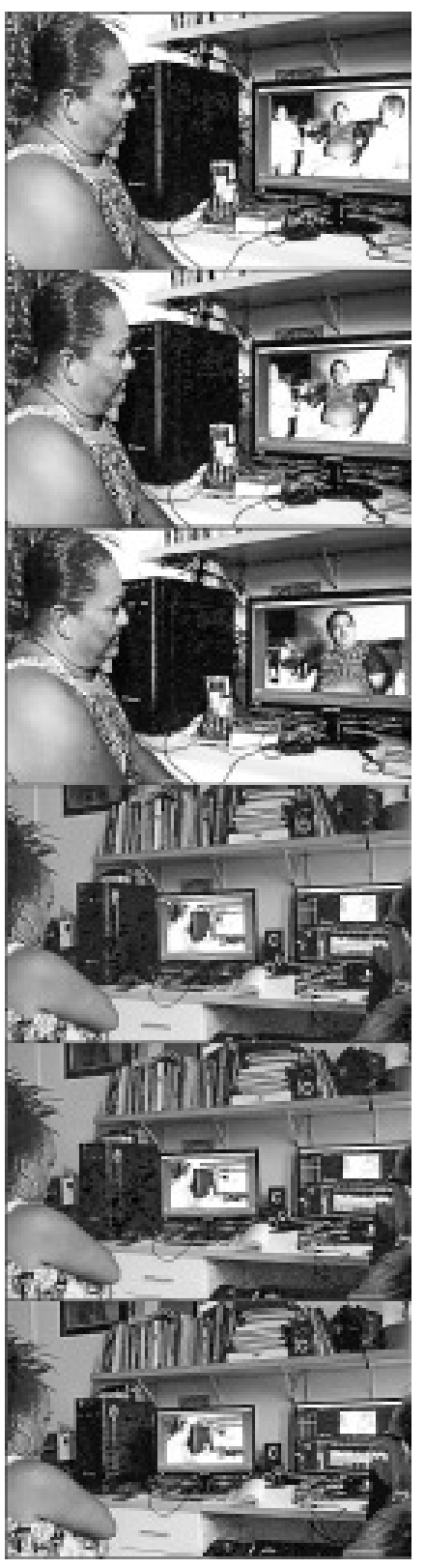

2 Para maiores informações, sugerimos a leitura de SAID, Edward. Permission to narrate. London Review of Books, p. 1317, 16-29 Feb. 1984 e SAID, Edward. Representing the Colonized: Anthropology's Interlocutors. Critical Inquiry, v. 15, p. 205-225, 1989.

3 Para maiores informações, sugerimos a leitura de SPIVAK, Gayatri Chakravorty. Pratical Politics and the Open End. In: SPIVAK, Gayatri Chakravorty. The Postcolonial Critic: Interviews, Strategies, Dialogues. New York: Routledge,1990.

${ }^{4}$ Para maiores informações, sugerimos a leitura de BHABHA, Homi. The World and the Home. Social Text, v. 31/32, p. $141-153,1992$

${ }_{5}^{5}$ Para maiores informações, sugerimos a leitura de BATESON, Gregory e MEAD, Margaret. Balinese Character: a photographic analysis. New York: New York Academy of Sciences, 1942. 
No Brasil, Carvalho (2001) sinaliza que, nos anos de 1990, a partir do ingresso na academia de pais de santo, índios, capoeiristas, líderes sindicais, feministas, temos a produção de uma escrita que produziria uma ruptura entre nativos/as e os/as antropólogos/as, possibilitando o que Carvalho (2001) nomeou como mudar a origem do olhar. Exatamente nesse ponto polêmico de uma epistemologia situada na experiência é que nos interessa alterar a "origem do olhar" na história do movimento de travestis e transexuais que entrecruza e enlaça a história singular de Keila Simpson.

Acionamos o conceito de colonialidade do saber (Aníbal QUIJANO, 2005), embora outros campos disciplinares e outras abordagens teóricas tenham apresentado críticas ao modelo de ciência que incorpora as características modernas do conhecimento, tais como cientificidade, rigor metodológico, neutralidade e a autoridade como expressão do desenvolvimento histórico da sociedade europeia, herança de um modelo positivista anterior à discussão proposta por este autor. O conceito nos pareceu útil porque nos convida a examinar as ferramentas conceituais que permanecemos utilizando, ainda que supostamente com olhar emaranhado.

Dialogando com este trabalho do Jean Rouch construímos um filme documentário que propõe diferentes pontos de origens dos olhares marcados nesse encontro. Não estávamos dizendo de um outro, cujos marcadores de diferença são acionados a partir do encontro norte/sul, mas também não estávamos todos no mesmo lugar que posicionava Keila, única travesti entre nós. Reconhecer nesse encontro um nós enlaçado em pontos nodais com cruzamentos de raça/etnia, gênero, classe social, orientação sexual, escolaridade que subverte as posições entre as qualificações aceitas e destinadas foi reposicionar-se entre elementos e momentos do discurso e avenidas bem sedimentadas com as sensibilidades partilhadas em um processo articulatório (Ernesto LACLAU; Chantal MOUFFE, 1985). Como sublinhou Jacques RANCIÈRE (2014), há dois tipos de trabalho intelectual, um que intenta constituir um "tecido sensível da possibilidade de um mundo distinto e intervenções que intentam reescrever uma situação" (p. 215). Portanto, buscamos construir uma narrativa que (re)apresentasse histórias de travestis e transexuais brasileiras inseridas num complexo emaranhado discursivo que reverbera mais familiaridades, cotidianos e sensibilidades compartilhadas do que aquelas que são muitas vezes (re)enquadradas como estranhamentos para reescrever uma situação.

Embora Keila seja a personagem principal do filme e integrante na equipe deste texto, suas narrativas atravessam e entrelaçam os fios teóricos que escolhemos para compor essas experiências; todos/as somos responsáveis pelo documentário que resultou da pesquisa. Nossas narrativas também compuseram o filme, na escuta e reposicionamento das histórias, nas escolhas e identificação dos temas que gostaríamos de contar e esconder, nas sugestões de montagem, nas decisões sobre destaques a serem considerados. As decisões, desde a perspectiva teórica que norteou a construção do filme, foram sendo forjadas na equipe.

Ainda que nos apoiemos em Rouch, nosso trabalho vai além quando Keila Simpson participa não apenas da direção, mas também da edição do filme. Ao imprimir no resultado final do documentário suas impressões narrativas e estéticas, ela, juntamente com o pesquisador/ cineasta, diz como gostaria de ser vista, organiza a narrativa e cria uma ficção a respeito. Neste sentido, a noção de decolonialidade adquiriu outros tons tanto em relação ao trabalho de Rouch quanto à critica sobre a relação pesquisador/sujeito pesquisado. O ponto nevrálgico aqui foi assumir a igualdade, não como um valor a ser alcançado através da tarefa conjunta que já parte da classificação desigual, mas como um princípio articulador de reposições, alternador da origem do olhar, por isso subversivo e desorganizador frente às posições historicamente classificadas.

Para a escrita do artigo, o processo não foi diferente. A partilha de textos e de conceitos se deu amarrando formações teóricas em diferentes narrativas que agora materializam-se em texto. Filme e artigo são suportes distintos que possibilitam circular diferentes sentidos entre a mistura de narrativas que mobilizou debates e sensibilidades próprias como consequências dessa experiência entre a travestilidade, a memória, a transexualidade, a produção acadêmica e a história do movimento social.

\section{Estratégias em movimentos}

As narrativas sobre a construção do movimento nacional de travestis e transexuais enlaçam enfrentamento à epidemia HIV/AIDS, a presença e interlocução com pesquisadoras/es, o mundo acadêmico e o movimento das pautas de vida/luta. Recontar e contar essa história exigiu um exercício de deslocamento e proposta de construção de planos de aproximação que não se remontam necessariamente a uma ordem cronológica, embora ela esteja presente no suporte dos textos acadêmicos.

Para esse trabalho, foram trançados os fios entre encontros, entrevistas, memórias partilhadas por entre o movimento de travestis e transexuais narrados durante a realização do documentário e a consulta a textos acadêmicos e não acadêmicos que documentaram passagens históricas do movimento. Foram acionadas lembranças, afetos, confusões e lágrimas que, dispersas na 
cronologia do tempo, reconstroem, através das narrativas da experiência, uma história que foi negada pela aspereza do olhar colonizado. Assim, o que nos interessa é menos a ordem dos fatos e mais o emaranhado que eles constituem ao reatualizar a memória sensível do movimento. Por esse motivo, assumimos que essa história pode sequestrar fatos e até datas porque ela está baseada numa epistemologia que não se pretende totalizadora, mas, muito pelo contrário, se narra como objetivamente situada na experiência, desvelando um emaranhado das lembranças fraturado pelas emoções das recordações. As travestis e transexuais, reconhecidas como lideranças mais antigas, contaram seus relatos e compartilharam suas vivências com muitos pesquisadores/as, representantes de governos, profissionais de saúde e, principalmente, com as travestis e transexuais participantes dos eventos, embora nem todas se percebam ou sejam percebidas como militantes.

Jovanna Baby foi considerada uma pessoa fundamental para a recuperação dessas memórias. Durante sua fala na mesa-redonda ${ }^{6}$ organizada para abordar o histórico do movimento, entre nomes de autoridades e datas das ocorrências, o que pareceu sensibilizar a audiência foram os relatos de violências, particularmente aquelas perpetradas pela polícia. Posicionadas entre o passado e o presente, as narrativas da violência policial arrancavam expressões da plateia, ora assustada, ora incrédula e pareciam reatualizar situações possíveis para quem permanece nos marcos da precariedade. A marcha realizada no final do III Encontro Nacional de Travestis e Transexuais na luta contra a aids (Entlaids) no Rio de Janeiro, em 1985, e recontada por Jovanna Baby, denunciava o assassinato de oito travestis e parece remeter a um cenário ainda contemporâneo: "as travestis saíram da Candelária gritando em coro as palavras de ordem: ata ata ata a polícia que nos mata... ina ina ina a policia é assassina".

Importante esse marco histórico das narrativas, pois expressa que a mobilização das travestis e transexuais, embora reconhecida a partir e com a emergência da aids, foi anterior, pelo embate com a polícia e o enfrentamento contra violência estatal. O cenário das ruas, da prostituição e das performances da noite foi, sem dúvida, o mesmo que transformou as avenidas em luta política por direitos de ser, expandindo, muitas vezes, o direito a existir.

\section{O enfrentamento da epidemia}

Uma década separa o XIV Entlaids, ${ }^{7}$ de 2007, da escrita deste texto. O evento retornava a São Paulo também após uma década em que a cidade havia sediado o encontro. A lembrança que queremos discutir está na atividade extraoficial que não poderia poluir uma pauta que mobilizaria o evento naquele ano e se ancorava na explícita tentativa de materializar uma divisão entre as travestis e as mulheres transexuais (Flavia B. TEIXEIRA, 2013). No entanto, não seria essa a pauta que mobilizava os espaços fora da agenda.

Das discussões travadas sobre prostituição e cafetinagem surgiu o convite para que fôssemos conhecer uma experiência que se iniciava em São Paulo inspirada no modelo da Casa Brenda Lee. ${ }^{8}$ Tratava-se de um prédio de alguns andares, situado em algum ponto da zona norte da cidade na Avenida Cruzeiro do Sul. Ao lado do prédio, no qual residiam muitas travestis, várias migrantes dos estados do Norte e Nordeste do país, havia uma casa pequena com poucos quartos e, apesar de limpos e organizados, não demonstravam oferecer conforto. Esse era o ponto de contato com a experiência da Casa Brenda Lee; em alguns desses quartos eram acolhidas travestis que apresentavam sinais de adoecimento em razão da aids. Essas travestis e transexuais (e a sua permanência na casa) eram mantidas por um sistema de solidariedade compulsória, ou seja, parte das diárias recebidas pela dona da pensão era revertida em contribuição para a casa. As moradoras da pensão não eram consultadas sobre a doação, a proprietária estabelecera uma taxa e o argumento era o de que 'hoje são elas, amanhã poderia ser qualquer uma das outras'. 9

A experiência, iniciada duas décadas depois da Casa Brenda Lee, demonstrava que o problema de apoio enfrentado pelas travestis e transexuais vivendo com aids não havia sido superado (Lindinalva LAURINDO-TEODORESCU; Paulo TEIXEIRA, 2015, p. 223-224). Não tivemos mais notícias sobre essa experiência, apenas uma matéria veiculada, em 2011 , no Jornal "A Folha de São Paulo", sobre a ação da polícia da capital paulista, envolvendo a investigação sobre tráfico de pessoas/cafetinagem que sugere se referir ao mesmo local, que foi fechado na operação.

\footnotetext{
${ }^{\circ}$ Durante o VII ENCONTRO REGIONAL DE TRAVESTIS E TRANSEXUAIS DO TRIÂNGULO MINEIRO, em setembro de 2016, na cidade de Uberlândia.

7 Essa é nomenclatura atual; outras formas de nomear o evento integram o processo de construção do movimento. Para maiores informações, sugerimos a leitura das entrevistas de Jovanna Baby e Keila Simpson que constam na tese de Gilson Goulart Carrijo (CARRIJO, Gilson Goulart. (Re)apresentaçóes do outro: travestilidades e estética fotográfica. 2012. Tese (Doutorado em Multimeios) - Programa de Pós-Graduação em Multimeios, Universidade Estadual de Campinas, Campinas, SP).

${ }^{8}$ Instituição conveniada com a Secretaria Estadual de Saúde desde 1988, criada pela travesti Brenda Lee e que manteve seu nome em homenagem à sua luta. É reconhecida como a primeira iniciativa de assistência domiciliar para as pessoas que viviam com aids em meados dos anos de 1980 (LAURINDO-TEODORESCU; TEIXEIRA, 2015).

${ }^{9}$ Memória compartilhada com o grupo durante a edição do documentário.
} 
A acusação de cafetinagem sempre atravessou os bastidores dos Entlaids, hora marcando uma integrante, uma liderança, uma palestrante e, outras vezes, em tom jocoso em espaços de intimidade. Não iremos nos deter nessa questão nesse momento, mas estabelecemos uma articulação para demonstrar que, em 1985, Brenda Lee, com sua experiência de acolhimento coletivo, se fosse interpelada pelo Código Penal, poderia ter sofrido a mesma acusação, conforme lembra Flavia B. Teixeira (2008).

Brenda Lee não aparece nas narrativas como militante do movimento das travestis e transexuais. A sua atuação no enfrentamento à epidemia da aids produziu um reconhecimento vinculado ao campo da atenção em saúde e assistência social. Entre a fundação da instituição e sua morte, a Casa de Brenda se tornou um equipamento fundamental para a rede estadual de saúde, embora seu ativismo não tenha necessariamente transformado o espaço em um lugar de formação da militância (LAURINDO-TEODORESCU; TEIXEIRA, 2015; João Silvério TREVISAN, 2000). No entanto, vale ressaltar que a experiência coletiva organizada por Brenda Lee teve seu reconhecimento junto às políticas de enfrentamento à aids, médicos e profissionais da saúde, transformando a experiência de moradia coletiva em um espaço de aprendizagem sobre as formas políticas de enfrentamento à aids, à organização das políticas públicas e à participação e formação dos diferentes profissionais nesse espaço.

Em 1997, o Grupo Filadélfia de Santos (SP) organizou $\circ \mathrm{V}$ Entlaids na cidade de São Paulo em parceria com o Centro de Referência e Treinamento em DST/ AIDS (CRT-DST/Aids) de São Paulo (Alessandro Soares SILVA; Renato BARBOZA, 2009). Indianara Siqueira, reconhecida liderança trans, recupera que o apoio se deu mediado pela Casa de Apoio Brenda Lee. ${ }^{10}$ Esse fio narrativo nos ajuda a pensar nas relações afetivas e de solidariedade que foram (e são) tecidas pelas travestis e que também compuseram processos pouco reconhecidos nas atividades militantes, que apontam para a autonomia e capacidade de articulação mediadas pela necessidade de

Foto 2: IV Encontro, Rio de Janeiro, 1996. Da esquerda para direita: André Fernandes, Jovanna Baby, Indianara Siqueira e Kátia Tapety.

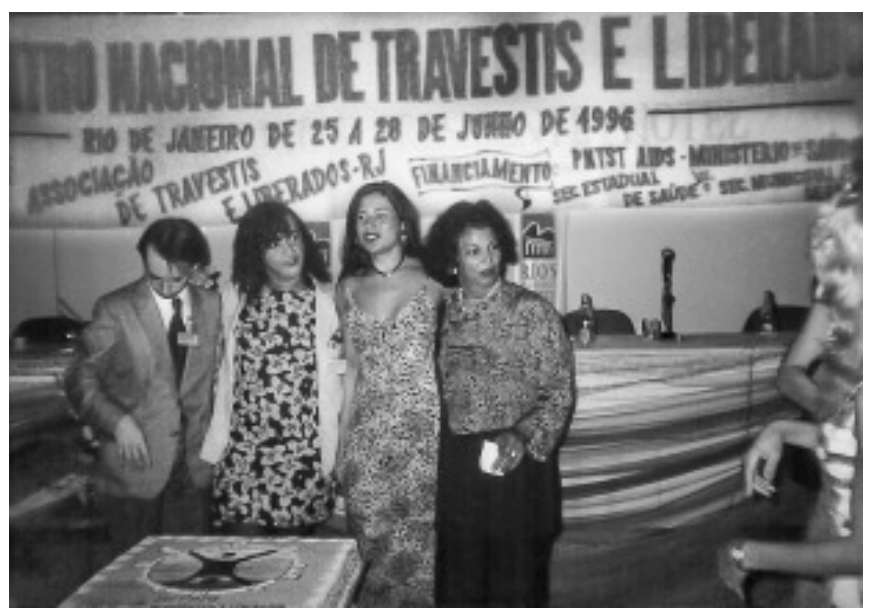

Fonte: Arquivo pessoal de Keila Simpson

enfrentamento da aids, mas não unicamente presos a ela. Ou seja, pode-se afirmar que na experiência do movimento de luta das travestis no Brasil há várias ações de solidariedade que foram gestando formas de ativismo e participação políticas mesmo que estas não correspondam às clássicas categorias de análise das militâncias, o que vai delineando não só uma forma relativamente autônoma de organização como também bastante nova no repertório das ações políticas que vão, historicamente, sendo desenhadas naquele momento.

O enfrentamento da epidemia da aids demarca as narrativas de Indianara Siqueira sobre sua participação no movimento organizado de travestis e no movimento de prostitutas em Santos/ SP. Também tendo trabalhado na estratégia de prevenção da aids vinculada ao Programa Municipal de DST/Aids da cidade de Santos, ela integrou o grupo de travestis que participou do III Encontro representando o estado de São Paulo em 1995 já na condição de Presidenta/Fundadora do Grupo Filadélfia de Travestis e Liberados da Baixada Santista. Chegar no encontro já representando uma organização sugere que os movimentos estavam ocorrendo em diferentes locais do país. Jovanna Baby relatou que, em 1993, quando começou a contatar as travestis, a partir de diferentes estratégias de comunicação, para participarem do II Encontro, em Vitória, ela percebeu que muitas já militavam na distribuição de insumos e junto aos postos de saúde de suas cidades de origem. Esse processo de identificação foi ocorrendo também nos encontros posteriores. Mario Felipe de Lima CARVALHO (2011) apontou que, embora as travestis tivessem sido inseridas em diferentes projetos/ações locais de enfrentamento da epidemia da aids, todas foram atravessadas por essa agenda inicialmente financiada por organismos internacionais.

Entre os anos de 1995 e 1996, Porcina D'Alessandro foi identificada como uma liderança travesti trabalhando com prevenção à aids em Belo Horizonte, junto ao Grupo de Apoio e Prevenção

\footnotetext{
${ }^{10}$ Resposta da ativista em interpelação na mesa-redonda organizada durante o VII ENCONTRO REGIONAL DE TRAVESTIS
} E TRANSEXUAIS DO TRIÂNGULO MINEIRO, em setembro de 2016, na cidade de Uberlândia. 
à aids (GAPA) daquela cidade. Ela participou do IV Entlaids, em 1996, representando as travestis de Belo Horizonte e, em 1999, seria uma das responsáveis pelo nascimento da Associação das Travestis de Minas Gerais - ASSTRAV - em Belo Horizonte, com apoio de Jovanna Baby e outras ativistas que estavam no Rio de Janeiro, como, também, com o apoio de grupos gays que se organizam naquele momento na cidade de Belo Horizonte (Frederico Viana MACHADO, 2007).

Keila Simpson desembarcou pela primeira vez no IV Entlaids na cidade do Rio de Janeiro em 1996. Segundo Neuza OLIVEIRA (1994), na década de 80 , na cidade de Salvador, o poder público ensaiava algumas ações para o enfrentamento da epidemia da aids com as travestis. Assim como ocorrera com Indianara e muitas outras, Keila fora identificada como liderança para trabalhar o modelo de educação pelos pares na prevenção da aids. Representante da Bahia, ela trazia nas credenciais a referência do Grupo Gay da Bahia (GGB). Embora o GGB naquele momento fosse uma Organização Não Governamental (ONG), ${ }^{1}$ a referência para Keila (e outras travestis da cidade de Salvador) seria o professor Luís Mott, triangulando as ações mediadas por instituições de ensino superior, órgãos públicos e as travestis.

Uma relação que também se estabelecera no Rio de Janeiro era o Instituto Superior de Estudos da Religião, ISER, ligado à diocese do Rio de Janeiro, que desenvolvia um projeto de prevenção de HIV/aids com distribuição de insumos para as mulheres nos espaços de prostituição. Naquele contexto, Jovanna Baby foi convidada para trabalhar como mediadora do projeto, tornando-se a referência para as travestis a partir de 1990. A parceria entre o ISER e as travestis e transexuais possibilitou a criação da Associação de Travestis e Liberados do Rio de Janeiro (ASTRAL), da qual Jovanna foi a presidenta e a realizadora do primeiro Encontro Nacional de Travestis e Liberados (ENTLAIDS), em 1993, no hotel Glória, na cidade do Rio de Janeiro. Esse evento demarca a construção do movimento social organizado das travestis e transexuais brasileiras, no entanto, é o Encontro de 1996 que ocupa o imaginário como sendo o "Encontro da Santíssima Trindade". 12

Assistir ao documentário possibilita ao espectador perceber o impacto do reencontro 20 anos depois. Visivelmente emocionadas, elas dizem desse lugar de afetos, rupturas e continuidades nessa história.

Foto 3: Frames do documentário "Um atentado violento ao pudor", dirigido por Gilson Goulart e Keila Simpson, Brasil - 2017. Da esquerda para direita: Keila Simpson, Indianara Siqueira e Jovanna Baby.

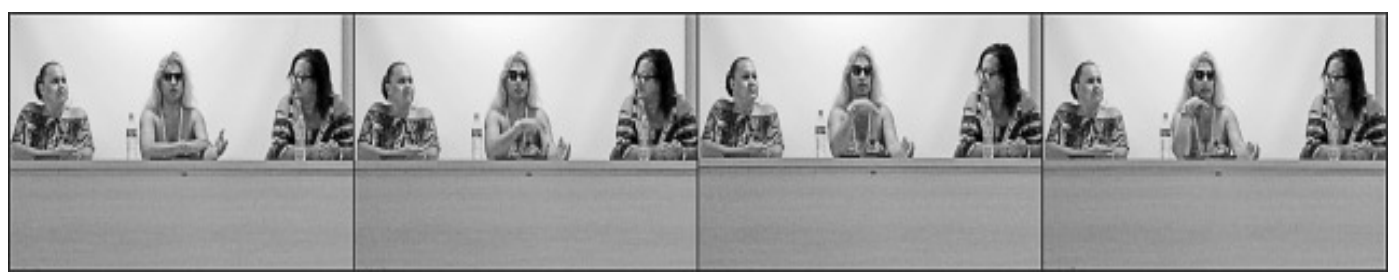

Celebravam o fato de terem sobrevivido para contar a história. Não era da aids que elas estavam dizendo, mas das violências que enfrentaram.

\section{Pautas de luta e vida}

Pouco visibilizado nas narrativas oficiais, o segundo encontro realizado em Vitória/ES, em 1993, possui singularidades que apontam para o tema da violência e suas reapresentações e atualizações no cotidiano das travestis e transexuais.

Compreender o deslocamento do Encontro Nacional de Travestis e Liberados para Vitória, no estado do Espírito Santo, exige perceber os trânsitos e os arranjos afetivos e de resistência que as travestis e outros grupos foram construindo. Jovanna Baby residira em Vitória no período de 1979 a 1983. Nessa oportunidade organizou, com as mulheres prostitutas, a criação da Associação Damas da Noite, tendo Bianca como primeira presidenta.

Foi essa articulação que facilitou a participação de uma representante da Secretaria de Justiça do Estado do Espírito Santo, Departamento de Apoio às Minorias (DEAMI) no primeiro encontro realizado no Rio de Janeiro. A presença dessa representante foi decisiva para que o governo do estado apoiasse integralmente a realização do II Encontro Nacional de Travestis e Liberados em Vitória.

Em tempos de comunicação por telefone e carta, destacamos a capacidade de articulação política de Jovanna Baby que, mesmo residindo no Rio de Janeiro, organizou o evento em outro Estado. Esse se tornou o único encontro nacional do Entlaids cujo mote de organização esteve desvinculado do enfrentamento da epidemia da aids.

\footnotetext{
${ }^{11}$ O endereço eletrônico à época era http://www.ggb.org.br/ggb.html.

${ }^{12}$ Renomeado posteriormente por Indianara Siqueira como o Encontro da Putíssima Trindade, embora as outras duas integrantes permaneçam nomeando como anteriormente.
} 
Se a violência policial parece constituir um amálgama que homogeneíza a experiência das travestis e transexuais em diferentes cidades brasileiras naquele momento, serem transportadas em carros oficiais da polícia militar (PM) e partilharem do alojamento destinados a eles produziria um efeito simbólico que marcaria o II Encontro Nacional das Travestis e Liberados. Essa participação da PM pouca mudança operacionalizou na prática e a violência policial atravessa a pauta e se conforma a partir e na interação com o movimento.

Em 2006, o XIII Entlaids foi sediado em Goiânia e o motivo da escolha da cidade foi ancorado nas denúncias de violência perpetrada por policiais militares contra as travestis. No início do evento, fomos apresentadas ao cenário que dava concretude aos argumentos utilizados pela então presidenta da Associação Nacional de Travestis e Transexuais (ANTRA).

Flavia B. Teixeira, pesquisadora da Universidade Federal de Uberlândia, estava sentada no hall do hotel com algumas travestis que saíram do Rio de Janeiro e lhe deram carona no ônibus que passou por Uberlândia, organizado por Majorie Marchi. ${ }^{13}$ Havia recebido um "código de conduta" para participar do evento que também integrava o Regimento do mesmo e parecia tentar compreender como um "manual de boas maneiras" que se constituiria numa peça-chave no encontro. Orientações como se vestir para circular no hotel, horários em que deveriam estar presentes nas atividades, proibição de uso de álcool e outras drogas nos quartos do hotel, bem como as prováveis punições para transgressões das normas, constavam no documento que acabara de ser aprovado - sem questionamento - como primeira atividade do Encontro.

A presença intempestiva de policiais militares na recepção do hotel produziu uma movimentação diferenciada. Uma policial aparentemente irritada e falando em tom bastante alto questionava a presença das travestis e transexuais e a realização do Encontro. Ninguém conseguiu se aproximar o suficiente para compreender o que teria deflagrado a entrada da polícia e nem mesmo seu processo de retirada. O entendimento é que aquela seria uma ação de intimidação, de demonstração de força. Keila, que se manteve junto à responsável pelo evento, se encarregou posteriormente de explicar os fatos aos que tentavam compreender o episódio relatado acima. A referida agente pública integrava o grupo de policiais responsáveis por abordagens violentas com as travestis e transexuais nas ruas de Goiânia. Agressões com correntes, suspensão das pessoas pelas calcinhas, além do fato de que uma travesti havia sido baleada e estava paraplégica, fato atribuído a esse grupo. Aquela noite seria plantão da referida policial que, abordando as travestis (como fazia recorrentemente), estranhou o aumento significativo delas nas ruas e, principalmente, no entorno do hotel. O episódio teve desdobramentos imediatos: a então Secretaria dos Direitos Humanos da Presidência foi acionada e o fato relatado. Na manhã seguinte uma comissão formada por várias lideranças travesti (entre elas, Keila) foi recebida pelo então secretário de segurança pública do estado. O imediato afastamento da policial das ruas e o compromisso de que essa abordagem não era autorizada e não integraria os procedimentos formais da corporação foram os efeitos dessa mobilização. ${ }^{14}$

A violência policial atravessa as narrativas de Indianara Siqueira, Jovanna Baby e Keila Simpson. O que parece ter se deslocado aqui seria a possibilidade de denunciar a ação dos policiais como sendo abusivas, mesmo sem garantias de resultados efetivos.

Valéria Melki BUSIN (2015) identifica que os policiais permanecem sendo recontados como principais agentes agressores das travestis. Não serão mais as cordas de caranguejo realizadas à luz do

Foto 4: Foto 4: Quartel do Derby - II Semana Nordestina de Visibilidade Trans, Recife, 2015.

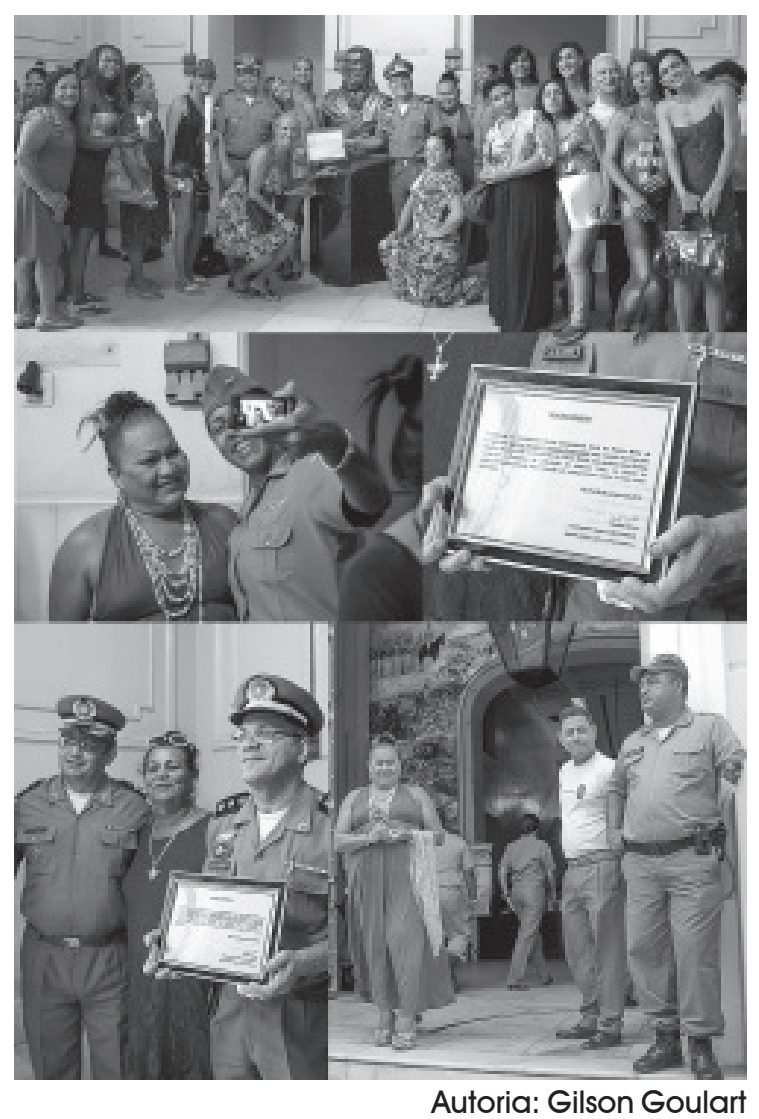

\footnotetext{
${ }^{13}$ Referência para militância travesti e transexual do Rio de Janeiro, falecida em 2012.
}

${ }^{14}$ Memória compartilhada com o grupo durante a edição do documentário. 
dia em Salvador, como relata Keila SIMPSON (2015), ${ }^{15}$ nem ser amarrada ao poste como ocorrido com Indianara na cidade de Santos. A incerteza de que serão protegidas, ou melhor, que não serão violadas por agentes do estado segue marcando o cotidiano das travestis com a violência institucional. Dados de pesquisa (PRADO et al., 2016) mostram que agentes de segurança do Estado como policiais são um dos principais agentes do ciclo de violência sofrida pelas travestis e transexuais até hoje. E o são não somente os agentes, mas, também, os silenciadores das violências que tentam se forjar em denúncias formais. Casos como os de Verônica Bolina (Kleber TOMAZ; Glauco ARAúJO, 2017) e Laura Vermont (PRAGMATISMO POLíTICO, 2015) funcionam como alertas sobre a precariedade com que suas vidas são enquadradas nos marcos de inteligibilidade.

Embora os Entlaids sejam reconhecidos como os principais eventos nos quais as travestis e transexuais se reúnem, outros eventos demonstram que elas ampliaram os espaços de luta. Uma comitiva percorreu o estado de Pernambuco na II Semana Nordestina de Visibilidade Trans no período de 24 a 31 de janeiro de 2015. Entre as ações organizadas pela Articulação e Movimento para Travestis e Transexuais de Pernambuco, AMOTRANS, estava a II Marcha para visibilidade de pessoas trans que finalizava no Quartel do Derby com uma cerimônia que anunciava uma homenagem das pessoas trans ao Coronel e firmava um compromisso de luta contra a discriminação e a violação de direitos humanos das travestis e transexuais. A recepção no espaço do alto comando da Polícia Militar indicaria a atualidade da reivindicação de existência e a persistência da pauta.

Ainda que, aparentemente distante do campo da aids, o evento acima desdobra da comemoração do Dia da Visibilidade Trans, definido como 29 de janeiro, sua origem está vinculada à Campanha Travesti e Respeito: já está na hora dos dois serem vistos juntos. Em casa. Na boate. Na escola. No trabalho. Na vida., lançada em 2004 como parte das ações estratégicas do então Programa Nacional de DST, HIV e Aids. Seis anos depois, uma nova Campanha foi lançada: Olhe. Olhe de novo. E veja além do preconceito. Sou Travesti. Tenho direito de ser quem eu sou., também vinculada ao Departamento de DST/AIDS e Hepatites Virais (Junny KRAICZYK, 2014). Apesar de concordarmos com Larissa PELÚCIO (2007) que o reconhecimento do Estado e a consequente inclusão das travestis se fazem a partir da aids, processo denominado pela pesquisadora como "sidadanização", as travestis e transexuais fizeram/fazem outros usos desses espaços (Keila SIMPSON, 2015). As Campanhas pouco circularam entre os destinatários - o que poderíamos, sem cuidado, avaliar como fracasso. Mas seu efeito não se encontra nesse lugar.

Essa forma que teve mais visibilidade do movimento de travestis e transexuais a partir da consequente inclusão delas na pauta do Estado com relação à aids é um excelente exemplo das fissuras e capturas que os movimentos sociais enfrentam no Brasil. Seja porque o campo dos direitos após os anos de 1980 irá sofrer uma maior judicialização e institucionalização, pautado sobretudo pelo neoliberalismo de mercado, seja porque o Estado aparece como campo de disputa de vários movimentos e posições políticas. ${ }^{16} \mathrm{O}$ risco é grande; aparecer como sujeito político nesse cenário é exatamente compor parte do risco entre a fissura e a captura. As travestis e sua movimentação política produzem atos políticos em lugares que não poderiam ser efeitos nem somente das fissuras de poderes excludentes, nem somente das capturas assimilacionistas do Estado, mas sim em um entre-lugar.

O lançamento da Campanha Livres e Iguais das Nações Unidas no Brasil marcou as comemorações do "Dia da Visibilidade Trans" nesse ano de 2017. Keila Simpson - com um turbante e um vestido estampado com a imagem de um indígena-acionou a interseccionalidade, apontando para o entrecruzamento das vulnerabilidades que posicionam travestis e transexuais em lugares desiguais. $O$ ingresso das travestis e transexuais na Câmara dos Deputados para o lançamento da Campanha em 2004 foi considerado o ato demarcatório. Estavam onde não deveriam estar e serem vistas ali foi um ato transgressor. Eram corpos nos lugares não destinados pelas lógicas hierárquicas do gênero e das sexualidades.

O discurso proferido por Keila Simpson causou comoção na plateia e, ainda, estava carregado de sangue. São as mortes das travestis e transexuais por violência que evidenciam o quanto os anos de 1993/2004/2017 estão, ao mesmo tempo, próximos e distantes, são um passado mais que perfeito e um pretérito do futuro. As travestis e transexuais ainda lutam para não serem mortas pela violência. A morte de Marina Garlen, uma das travestis de Salvador que compôs a militância soteropolitana, foi particularizada e ela nomeada como vítima do Estado pela negligência na oferta de cuidado em saúde. ${ }^{17}$

Travestis e transexuais ocuparam muitos outros espaços institucionais e políticos a partir de 2004. Foram os espaços de participação popular e controle social construídos inicialmente no

\footnotetext{
${ }^{15}$ Os policiais amarravam as travestis, unindo-as pelos braços ou pescoços, e desfilavam com elas pelas ruas até a chegada na delegacia.

${ }^{16}$ Sobre esse ponto, vale a leitura do diálogo de Sonia CORREA e Sergio Carrara e que está publicado em http:// clam.org.br/uploads/arquivo/1-\%20Dialogo\%20Sonia\%20Sergio\%2OPDF.pdf sob o título "Referências que continuam inspirando", acessado em 26 de agosto de 2017.
} 
campo da saúde que parecem ter produzido a visibilidade e a efetiva possibilidade de defesa das pautas do movimento social. ${ }^{18}$ Essas participações foram também sendo oportunidades de práticas educativas na militância, nas instalações de negociações estratégicas e nas potencialidades de parcerias com diferentes agentes públicos. Um movimento que vai se formando nas fronteiras entre o Estado e a Sociedade Civil e estabelecendo entre as oportunidades políticas e as configurações de identidades coletivas ações que estratégica e simbolicamente configuram um campo de disputas nas bordas da política (Marco PRADO; Frederico MACHADO, 2014).

A participação das travestis em espaços de discussão da política de enfrentamento da epidemia da aids tais como Comitês Assessores e Grupos de Trabalhos é percebida por elas como um exercício de aprendizagem das ferramentas conceituais e modos de funcionamento da gestão que posteriormente serão aprimorados. Comitê Técnico da Promoção da Política de Equidade, Conselho Nacional de Saúde, no âmbito do Comitê Intersetorial de Saúde da População LGBT (CISP/LGBT), Conselho Nacional de Segurança Pública e Conselho Nacional de Combate à Discriminação e Promoção dos Direitos de LGBT foram alguns dos espaços ocupados pelas travestis nos últimos 10 anos. Essas lógicas foram produzindo, por um lado, uma estratégia técnica e um trânsito das linguagens e mecanismo dos poderes e, por outro, um distanciamento, muitas vezes, daquela atuação nos campos de trabalho e mobilização que antes eram mais evidentes.

Essas posições são valorizadas durante os Entlaids, sendo que é reservada uma participação nas mesas para as integrantes de Comitês, GTs e/ou Conselhos. Fernanda Benvenuty integrou o Conselho Nacional de Saúde, representando a ANTRA como suplente, no período de 2014 a 2016. Apesar do pouco tempo (um único mandato) no último Entlaids, realizado em 2016, na cidade de Campo Grande, ela era apresentada como a "eterna conselheira de saúde". Compreender o lugar construído para Fernanda exige pensar que sua profissão como técnica de enfermagem produziu um efeito de possibilidade de estar em outros espaços para as travestis, assim como também relata Marcelly Malta em sua experiência em Porto Alegre, no Rio Grande do Sul. Ambas iniciaram a militância nos seus espaços de trabalho, mediando a relação entre as travestis e os serviços de saúde.

Integrar esses espaços significou também acompanhar a construção das políticas públicas, principalmente aquelas vinculadas ao Ministério da Saúde. Os trânsitos entre eventos organizados

Foto 5: Mosaico de lutas.

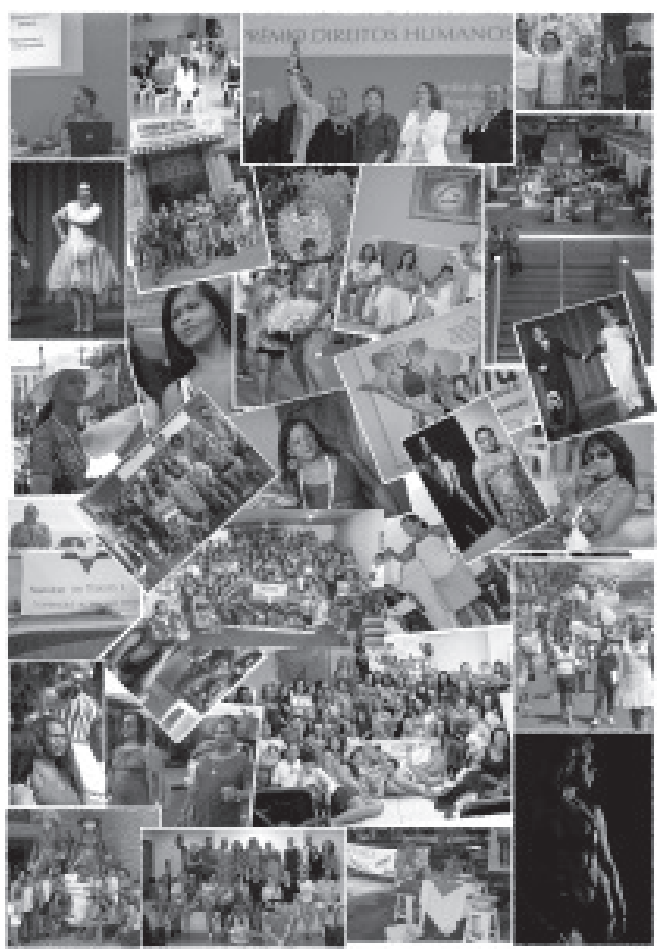

Autoria: Gilson Goulart pela gestão federal e/ou instituições de ensino traçaram linhas que produziam muitos dos nossos encontros. Dividimos mesas, debates nas universidades, conversas acadêmicas, espaços na plateia, salas de aulas e quartos de hotéis e, assim, fomos compondo nossa rede de relações.

\section{(Des)encontros e silenciamentos}

Não foram os/as pesquisadores/as que buscaram, inicialmente, as travestis e transexuais para construírem uma aliança, embora muitas/ os pesquisadoras/es se inseriram no movimento e participam com um ativismo acadêmico seja em função de pesquisas, interesses e aprendizados. A primeira relação institucional delas foi com o Estado, ainda que fosse uma relação indireta, mediada por várias organizações não governamentais ou instituições que desenvolviam ações para o enfrentamento da epidemia. A chegada até elas também não se deu via movimento LGBT. Foram as calçadas da prostituição que tornaram as travestis e as transexuais visíveis para o poder público. Apesar disso, prostituição e aids foram se constituindo em duas temáticas de difícil aceitação nos Entlaids quanto mais o evento contava com a participação regulada pelo Estado.

\footnotetext{
${ }^{17} \mathrm{O}$ evento foi registrado para o documentário, o que permitiu ao grupo rever as cenas e construir a narrativa sobre ela. 18 Importante ainda destacar que também espaços políticos formais como vereanças, assembleias legislativas e lugares do poder executivo em diferentes estados também foram ocupados pelas travestis e transexuais, culminando nas eleições de 2016 com um número alto de eleitas como vereadoras. Para mais informações, ver PRADO, Marco Aurélio Máximo (2016). Representação local e políica partidária: Candidaturas transexuais e travestis no Brasil. Dossiê SPW - Transexuais e travestis nas eleições de 2016. Rio de Janeiro. Disponível em http://sxpolitics.org/ptbr/representacaolocal-e-politica-partidaria-candidaturas-transexuais-e-travestis-no-brasil/6884. Acesso em 13/08/2017.
} 
As mortes e o adoecimento das travestis e transexuais em decorrência da aids são realidades que atravessaram o tempo, assim como a violência. Em certa medida as mortes e as violências se entrecruzam como efeitos e consequências da violência social, institucional e da violência letal do preconceito. O silenciamento sobre a aids é interessante. Posicionado no início da epidemia como motivador da mobilização das travestis, o tema desapareceu dos discursos, ainda que possamos identificar várias mortes como decorrentes da aids, incluindo as de militantes reconhecidas.

Os discursos que demarcam a aids como um problema para as travestis parecem enunciados a partir de dois lugares: o poder público e a academia. A recorrência do tema da aids/travestis como preocupação entre os/as pesquisadores/as foi identificada em diferentes revisões da literatura (Marília AMARAL et al., 2014; Gustavo RAIMONDI et al., 2016). Da mesma forma, apesar da dificuldade em ter acesso aos registros oficiais dos Entlaids, o enfrentamento da epidemia se constituiu na relação direta com o enquadramento das travestis como população vulnerável.

Embora pesquisadores tenham compreendido que a emergência do ativismo travesti tenha se caracterizado por um empoderamento tutelado (Mario Felipe CARVALHO; Sérgio CARRARA, 2013), nosso olhar, ao reconstruir esse emaranhado à luz de uma epistemologia situada e não cronológica, é outro: as estratégias que foram sendo traçadas evidenciam um ativismo emaranhado com autonomia, solidariedade e estratégias educativas. Parece-nos que o movimento das travestis e transexuais constituiu uma forma de autonomia capaz de transitar entre as linhas tênues de um ativismo emaranhado que, entre a ruptura e a captura, fez-se solidário, autônomo e sobrevivente. Tal característica é oriunda de uma habilidade de deslocamento cuja trajetória inicia nas relações que ocorrem nas bordas das políticas, nas fissuras entre o Estado e a Sociedade Civil - entre os agentes governamentais e programas de intervenção do Estado, seja nas áreas da saúde, educação ou segurança pública - e culmina em participações em comissões e comitês estatais e a relação com ONGs, movimentos sociais e organizações da sociedade civil.

Vimos, nesse emaranhado, que não foi o movimento LGBT que constitui esse movimento, muito pelo contrário; o movimento de travestis e transexuais entrou para o movimento LGBT, mas, ao mesmo tempo, se manteve com suas próprias ações, como é o caso do Entlaids e muitas outras. $O$ que não aconteceu com outros grupos de ativismo dentro do próprio movimento, que raramente mantiveram atividades singulares permanentes em tantos espaços sociais, governamentais, políticos e acadêmicos distintos.

Elas sempre impuseram suas pautas. Se para os outros era aids, para elas foi a violência, o "código de condutas" e a integralidade do cuidado em saúde. Muito antes que a Carta dos Direitos dos Usuários da Saúde (2006) ${ }^{19}$ estabelecesse o direito ao uso do nome social nos serviços de saúde, reconhecendo que esta seria uma estratégia para facilitar o acesso de travestis e transexuais aos cuidados em saúde, principalmente na Atenção Básica, essa pauta esteve presente no Entlaids de 1995, conforme registrou Hugo DENIZART (1997). Indianara Siqueira relata que, em 1996, na IV Conferência Municipal de Saúde de Santos, foram apresentadas propostas de inclusão do nome social das travestis nos serviços de saúde, reconhecimento da conjugalidade de gays e travestis para fins de acompanhamento em situação de consultas e internação, bem como a internação de travestis em alas femininas. ${ }^{20}$

A luta por inteligibilidade marcou, portanto, a pauta das travestis e resiste ao tempo. Direito, respeito, identidade, cidadania foram palavras que compuseram as teias narrativas dos diferentes encontros. No centro das demandas singulares, como a luta contra a violência estatal, o enfrentamento à aids, a organização das políticas trans específicas para a saúde, o direito ao nome social, a abertura dos mercados de trabalho, a formalização das denúncias de violências e tantas outras deixam nítido que esse ativismo emaranhado de tantas vozes instalou uma luta pela expansão dos limites da inteligibilidade e pela luta pelo direito de ser visível (Judith BUTLER, 2015).

\section{Conclusão}

O documentário produzido nesse entrelaçamento teve como efeito o resgate das lembranças do movimento somente porque ele produziu essa insistência em criar e experimentar sensibilidades de um mundo distinto, como diria Rancière (2014). Seu processo de produção colocou cientificamente em xeque ao menos três questões que nos parecem merecer destaque nesta conclusão: a relação entre sujeito e objeto; a posição de colonialidade do saber e a história de um movimento e de suas militantes.

Como Carvalho (2001) nos brindou, o deslocamento da origem do olhar faz-se numa ação científica e política fundamental para entender como a relação sujeito e objeto nos coloca em um patamar de discussão ética e política.

\footnotetext{
${ }^{19}$ Portaria MS n 675, de 30 de março de 2006.

${ }^{20} \mathrm{O}$ Relatório da $10^{a}$ Conferência Nacional de Saúde não incorporou nenhuma dessas propostas. As menções à gênero e orientação sexual integram as propostas 12.4 e 14.1 atreladas ao princípio da determinação social do processo saúde-adoecimento-cuidado.
} 
A escrita deste trabalho possibilitou pensar em nós, pesquisadores/as periféricos/as e subalternizados/as (Gayatri SPIVAK, 2010) e nossa posição ao caminharmos com Keila Simpson. Não se tratava de lhe devolver um lugar de enunciação, mas construirmos juntos um lugar não de informante privilegiada, mas sim de alguém que, dominando os códigos, detinha a potência para girar o lugar de enunciação. Essa virada não se daria sem que também nós não produzíssemos torções ao desafiar a pretensão dos conceitos que informam nossos saberes performadores sobre as práticas das travestis e das transexuais. Saberes que se não obliteram a fala (como mostram os estudos sobre travestis e transexuais no Brasil), com certeza cerceiam a escuta e dificultam/impedem as alianças políticas. Saberes que muitas vezes apenas corroboram e legitimam, discretamente, os critérios de audibilidade daqueles que podem falar e daqueles que apenas serão vistos como expressões de dor e prazer (RANCIÈRE, 2014).

A história do movimento, as histórias dos movimentos. Sem dúvida, são muitas histórias passíveis de serem contadas, lembradas e registradas. A torção que o documentário nos impõe é pensar a história pela trajetória singular de Keila Simpson e seus afetos e ações. Esse deslocamento foi permitindo-nos conectar fios e linhas nesse emaranhado das lembranças para recontar uma história que, muito antes de ser classificada, deveria ser registrada como a história das experiências de dissidências que não se furtam ao lugar convocatório das hierarquias de gênero.

O filme, o texto, a história, a personagem, as lembranças, os/as autores/as, os textos acadêmicos, as falas registradas e filmadas em eventos, tudo parece emaranhar-se numa história singular da personagem de forma que não há origem nem começo, mas reinvenção e deslocamentos.

\section{Referências}

AMARAL, Marília dos Santos et al. "Do travestismo às travestilidades: uma revisão do discurso acadêmico no Brasil entre 2001-2010". Revista Psicol. Soc., v. 26, n. 2, p. 301-31 1, agosto 2014.

BUSIN, Valeria Melki. Morra para se libertar: estigmatização e violência contra travestis. 2015. Tese (Doutorado em Psicologia Social) - Programa de Pós-Graduação em Psicologia Social, Instituto de Psicologia da USP, São Paulo, Brasil.

BUTLER, Judith. Notes toward a performative theory of assembly. Cambridge: Harvard University Press, 2015.

CARVALHO, José Jorge de. "O olhar etnográfico e a voz subalterna". Revista Horizontes Antropológicos, v. 7 , n. 15, p. 107-147, julho 2001.

CARVALHO, Mario Felipe de Lima. Que mulher é essa?: identidade, política e saúde no movimento de travestis e transexuais. 2011. Dissertação (Mestrado em Saúde Coletiva) - Programa de PósGraduação em Saúde Coletiva, Instituto de Medicina Social, Universidade do Estado do Rio de Janeiro, Rio de Janeiro.

CARVALHO, Mario Felipe de Lima; CARRARA, Sérgio. "Em direito a um futuro trans?: contribuição para a história do movimento de travestis e transexuais no Brasil”. Revista Sex., Salud. Soc., n. 14, p. 319-351, agosto 2013.

COELHO, Sandra Straccialano. "Petit à petit ou das aventuras de Rouch através do espelho". Revista O Olho Da História, n. 23, novembro 2016.

DENIZART, Hugo. Engenharia Erótica: travestis no Rio de Janeiro. Rio de Janeiro: Jorge Zahar, 1997.

EHLERS PEIXOTO, Clarice. "Antropologia e Filme Ełnográfico: um travelling no cenário literário da antropologia visual". BIB, n. 48, p. 91-115, 1999.

KRAICZYK, Junny. A bioética e a prevenção da aids para travestis. 2014. Dissertação (Mestrado em Bioética) - Programa de Pós-Graduação em Bioética, Universidade de Brasília, Brasília.

LACLAU, Ernesto; MOUFFE, Chantal. Hegemony and Socialist Strategy: Towards a radical democratic politics. London: Verso, 1985.

LAURINDO-TEODORESCU, Lindinalva; TEIXEIRA, Paulo Roberto. História da aids no Brasil: a sociedade civil se organiza pela luta contra a aids. v. 2. Brasília: Ministério da Saúde/Secretaria de Vigilância em Saúde/Departamento de DST, aids e Hepatites Virais, 2015.

MACHADO, Frederico Viana. Muito além do arco-íris: a constituição de identidades coletivas entre a sociedade civil e o estado. 2007. Dissertação (Mestrado em Psicologia) - Programa de PósGraduação em Psicologia, Instituto de Psicologia, Universidade Federal de Minas Gerais, Belo Horizonte. 
OLIVEIRA, Neuza. Damas de Paus: o jogo aberto dos travestis no espelho da mulher. Salvador: EDUFBA, 1994.

PELÚCIO, Larissa. "Ativismo Soropositivo: A Politização da Aids". Ilha Revista de Antropologia, v. 9, n. 1/2, p. 119-141, 2007.

PRADO, Marco Aurélio Máximo; FREITAS, Rafaela Vasconcelos; CARNEIRO, Julia; SANTOS, Anne Rafaely Telmia; ALECRIM, Dennyr Jefferson Dutra; GEA, Karina Dias; OLIVEIRA, Lorena Hellen de; COSTA, Nicole Gonçalves da. "Travestis e Transexuais no Brasil: ciclos de violência, inteligibilidade institucional e efeitos da invisibilidade". In: VEIGA, Ana Maria; LISBOA, Teresa Kleba; WOLFF, Cristina Scheibe (orgs.). Gênero e Violências: diálogos interdisciplinares. 1. ed., v. 1. Florianópolis: Edições do Bosque, 2016. p. 238-263.

PRADO, Marco Aurélio M.; MACHADO, Frederico V. "Muito além do arco-íris: a constituição de identidades coletivas entre o Estado e a Sociedade Civil". Annual Review of Critical Psychology, n. 11 , p. 151-170, 2014.

QUIJANO, Aníbal. "Colonialidade do poder, eurocentrismo e América Latina”. In: LANDER, Edgardo (org.). A colonialidade do saber: eurocentrismo e ciências sociais: Perspectivas latino-americanas. Ciudad Autónoma de Buenos Aires: CLACSO, 2005. p. 227-278. (Colección Sur Sur)

PRAGMATISMO POLÍTICO. Polícia Militar. Farsa da PM no assassinato da transexual Laura Vermont é desvendada, 04/08/2015. Disponível em https://www.pragmatismopolitico.com.br/2015/08/farsada-pm-no-assassinato-da-transexual-laura-vermont-e-desvendada.html.

RAIMONDI, Gustavo A.; PAULINO, Danilo B.; TEIXEIRA, Flavia B. "O que importa? As Pesquisas Brasileiras no Campo da Saúde e as (In)visibilidades das Travestis e Transexuais". Saúde \& Transformação Social / Health \& Social Change, v. 7, p. 133-146, 2016.

RANCIÈRE, Jacques. El Metodo de La Igualdad: Conversaciones con Laurent Jeanpierre Y Dork Zabunyan. 1. ed. Cidade Autónoma de Buenos Aires: Ediciones Nueva Vision, 2014.

RAPAZOTE, João. "Antropologia e documentário: da escrita ao Cinema”. Doc On-line, n. 03, p. 82113 , dezembro 2007.

SILVA, Alessandro Soares; BARBOZA, Renato. "Exclusão social e consciência política: luta e militância de transgêneros no ENTLAIDS". Cadernos CERU, v. 20, n. 1, p. 257-276, 2009.

SIMPSON, Keila. "Transexualidade e travestilidade na Saúde". In: BRASIL. Transexualidade e travestilidade na saúde. Ministério da Saúde. Secretaria de Gestão Estratégica e Participativa. Departamento de Apoio à Gestão Participativa. Brasília: Ministério da Saúde, 2015. p. 09-16.

SPIVAK, Gayatri Chakravorty. Pode o Subalterno Falar? Belo Horizonte: EDUFMG, 2010.

TEIXEIRA, Flavia B. Dispositivos de dor: saberes poderes que (con)formam as transexualidades. São Paulo: Annablume/FAPESP, 2013.

TEIXEIRA, Flavia B. "L'Italia dei Divieti: entre o sonho de ser européia e o babado da prostituição". Cadernos Pagu, n. 31, p. 275-308, dezembro 2008.

TOMAZ, Kleber; ARAÚJO, Glauco. “'Agi como um animal acuado', diz transexual sobre ter arrancado a dentadas orelha de carcereiro". G1 São Paulo, 07/05/201 7. Disponível em https://gl .globo.com/ sao-paulo/noticia/agi-como-um-animal-acuado-diz-transexual-sobre-ter-arrancado-a-dentadasorelha-de-carcereiro.ghtml.

TREVISAN, João Silvério. Devassos no Paraíso. 2.ed. São Paulo: Record, 2000.

\section{Filmografia}

PETIT à Petit. Direção: Jean Rouch. Produção: Pierre Braunberger. Realização: Jean Rouch. Roteiro: Jean Rouch. França/Nigéria, Les Films de La Pléiade, 1971, 96 min.

UM atentado violento ao pudor. Direção: Gilson Goulart e Keila Simpson. Produção: Flavia Teixeira. Realização: Gilson Goulart. Roteiro: Gilson Goulart e Keila Simpson, 2017, 91 min. 
Gilson Goulart Carrijo (gilsongoulart@yahoo.com) é doutor em Multimeios da Universidade Estadual de Campinas com pesquisa cuja temática é a construção de sentidos na fotografia. Realizou Pós-Doutoramento na Universidade Federal de Uberlândia (bolsista CAPES/ PNPD) com a supervisão do Prof. Dr. Emerson Fernando Rasera.

Keila Simpson (presidencia.antra@gmail.com) é ativista do movimento organizado LGBT desde 1991, atuando, a partir de 1996, com o movimento organizado de Travestis e Transexuais. Atualmente é Presidenta da Associação Nacional de Travestis e Transexuais - ANTRA e Coordenadora Geral da Associação Baiana de Travestis e Transexuais - ATRAÇÃO. Presidiu o Conselho Nacional de Combate à Discriminação de Lésbicas, Gays, Bissexuais, Travestis e Transexuais - CNCD LGBT. Primeira Travesti a receber o prêmio Direitos Humanos 2013 da Presidência da República na sua $19^{a}$ edição.

Emerson Fernando Rasera (emersonrasera@gmail.com) é doutor em Psicologia pela Universidade de São Paulo (2004), com Pós-Doutorado pela University of New Hampshire (EUA) (201 1-2012). Professor Associado IV da Universidade Federal de Uberlândia e docente do Programa de Pós-Graduação em Psicologia. Foi presidente da Associação Brasileira de Psicologia Social. Bolsista de Produtividade/CNPq e Pesquisador Mineiro/FAPEMIG.

Marco Aurélio Máximo Prado (mamprado@gmail.com) é doutor em Psicologia Social pela Pontifícia Universidade Católica de São Paulo, realizou estágios internacionais em diferentes instituições, entre elas a Universidade de Massachusetts/Fundação Fulbright na Cátedra de Estudos Brasileiros. Professor Associado III da Universidade Federal de Minas Gerais. Docente do Programa de Pós-Graduação em Psicologia e coordenador do Núcleo de Direitos Humanos e Cidadania LGBT (NUH/UFMG). Bolsista de Produtividade/CNPq.

Flavia Bonsucesso Teixeira (flavia.teixeira@ufu.br) é doutora em Ciências Sociais pela Universidade Estadual de Campinas, pós-doutora pela Università degli Studi di Milano (2010) e do Núcleo de Estudos de Gênero PAGU/Unicamp (2017). Professora Associada I da Universidade Federal de Uberlândia e docente do Programa de Pós-Graduação em Saúde da Família.

\section{COMO CITAR ESSE ARTIGO DE ACORDO COM AS NORMAS DA REVISTA}

CARRIJO, Gilson Goulart; SIMPSON, Keila; RASERA, Emerson Fernando; PRADO, Marco Aurélio Máximo; TEIXEIRA, Flavia Bonsucesso. "Movimentos emaranhados: travestis, movimentos sociais e práticas acadêmicas". Revista Estudos Feministas, Florianópolis, v. 27, n. 2, e54503, 2019.

\section{CONTRIBUIÇÃO DE AUTORIA}

Gilson Goulart Carrijo - Concepção, coleta de dados e análise de dados, elaboração do manuscrito, redação e realização das entrevistas

Keila Simpson - Análise de dados, discussão dos resultados, elaboração do manuscrito e redação, participação, produção e edição do documentário discutido no artigo

Emerson Fernando Rasera - Análise de dados, discussão dos resultados, elaboração do manuscrito e redação

Marco Aurélio Máximo Prado - Concepção, análise de dados, elaboração do manuscrito e redação

Flavia Bonsucesso Teixeira - Concepção, análise de dados, elaboração do manuscrito e redação, produção do documentário discutido no artigo

\section{FINANCIAMENTO}

Bolsa CAPES/PNPD e apoio do Departamento de Vigilância Prevenção e Controle das IST, do HIV/ Aids e das Hepatites Virais (DIAHV) para a realização do documentário

\section{CONSENTIMENTO DE USO DE IMAGEM}

Sim 
GILSON G. CARRIJO, KEILA SIMPSON, EMERSON F. RASERA, MARCO AURÉLIO M. PRADO, FLAVIA B. TEIXEIRA

APROVAÇÃO DE COMITÊ DE ÉTICA EM PESQUISA

Não se aplica

CONFLITO DE INTERESSES

Não se aplica

LICENÇA DE USO

Este artigo está licenciado sob a Licença Creative Commons CC-BY Internacional. Com essa licença você pode compartilhar, adaptar, criar para qualquer fim, desde que atribua a autoria da obra.

\section{HISTÓRICO}

Recebido em 12/12/2017

Reapresentado em 02/09/2018

Aprovado em 08/1 1/2018 